\title{
TINJAUAN PENYEDIAAN DOKUMEN REKAM MEDIS DI RSUD Dr. SOEKARDJO KOTA TASIKMALAYA
}

\author{
Firzah Dika Andria ${ }^{1}$, Ida Sugiarti ${ }^{2}$ \\ ${ }_{1,2}^{1}$ Poltekkes Kemenkes Tasikmalaya \\ virzzaandria@gmail.com ${ }^{1}$, sugiarti.ida@gmail.com²
}

\begin{abstract}
Fast and precise services are the desire of consumers. The speed of document provision of medical records to the clinic can be an indicator in measuring satisfaction. Based on preliminary studies in dr. Soekardjo Kota Tasikmalaya found that the provision of medical record documents less than the maximum and delayed. The aim of this research is to determine the implementation of the provision of documents in the old patient medical records outpatient services. This research type is a descriptive study. Data collection used observation sheets, stopwatch, and interview guidelines. Sample size is 99 medical record documents with accidental sampling technique. The amount of sample is 99 document medical records with accidental sampling technique. Data were analyzed using univariate analysis. The results shows $63.64 \%$ late provision of medical record documents with an average time of 12.36 minutes, it exceeds the minimum standard service that is d"10 minutes. The groove of the provision of documents in the old patient medical records outpatient is $100 \%$ not appropriate. This is due to the amount of time a patient visits increased, less officer, less storage rack capacity, system alignment sequence and the absence of tracer. The conclusion is the provision of document medical record of old patients is late and the groove of the provision of documents in the old patient medical records outpatient is not appropriate. To solve those problems, it would be better if the service quality is improved, especially in the speed of medical records document provision.
\end{abstract}

Keyword: speed of services, average speed, groove.

\begin{abstract}
Abstrak
Pelayanan yang cepat dan tepat merupakan keinginan konsumen. Kecepatan penyediaan dokumen rekam medis ke poliklinik dapat menjadi indikator dalam mengukur kepuasan. Berdasarkan studi pendahuluan di RSUD dr. Soekardjo Kota Tasikmalaya ditemukan bahwa dalam penyediaan dokumen rekam medis kurang maksimal dan mengalami keterlambatan. Tujuan penelitian ini adalah mengetahui pelaksanaan penyediaan dokumen rekam medis pasien lama di pelayanan rawat jalan. Jenis penelitian ini adalah penelitian deskriptif. Pengumpulan data menggunakan lembar observasi, stopwatch, dan pedoman wawancara. Besar sampel adalah 99 dokumen rekam medis dengan teknik accidental sampling. Analisis data dengan analisis univariat. Hasil penelitian menunjukan $63,64 \%$ dokumen rekam medis terlambat penyediaannya dengan rata-rata waktu 12,36 menit, melebihi standar pelayanan minimal yakni d"10 menit. Alur penyediaan dokumen rekam medis pasien lama di rawat jalan 100\% tidak sesuai. Hal ini disebabkan karena jumlah kunjungan pasien lama meningkat, petugas yang kurang, kapasitas rak penyimpanan kurang, sistem penjajaran tidak berurutan dan tidak adanya tracer. Kesimpulannya penyediaan dokumen rekam medis pasien lama terlambat dan alur penyediaan dokumen rekam medis pasien lama di rawat jalan tidak sesuai. Untuk memecahkan masalah tersebut ada baiknya jika kualitas pelayanan lebih ditingkatkan khususnya dalam hal kecepatan penyediaan dokumen rekam medis.
\end{abstract}

Kata Kunci: Kecepatan penyediaan, rata-rata kecepatan, alur. 


\section{PENDAHULUAN}

Pelayanan kesehatan adalah setiap upaya yang diselenggarakan sendiri atau secara bersamasama dalam suatu organisasi untuk memelihara dan meningkatkan kesehatan, mencegah dan menyembuhkan penyakit serta memulihkan kesehatan perorangan, keluarga, kelompok, dan ataupun masyarakat (Depkes RI, 2009). Pelayanan merupakan kegiatan dinamis berupa membantu, menyiapkan, menyediakan dan memproses serta membantu keperluan orang lain (Wahit dan Nurul, 2011).

Menurut Sabarguna (2004), pelayanan yang cepat dan tepat merupakan keinginan semua konsumen baik pemberi pelayanan maupun penerima pelayanan. Kecepatan penyediaan berkas rekam medis di klinik juga dapat menjadi salah satu indikator dalam mengukur kepuasan. Semakin cepat rekam medis sampai ke klinik maka semakin cepat pelayanan yang dapat diberikan kepada pasien. Standar kecepatan pendistribusian rekam medis terhitung di mulai sejak pasien melakukan registrasi di pendaftaran sampai dokumen didistribusikan ke poliklinik. Mutu pelayanan kesehatan dapat dikatakan baik bila didukung oleh suatu sistem pengolahan rekam medis dalam mendapatkan kembali berkas rekam medis yang cepat dan tepat waktu sesuai dengan ketentuan yang telah ditetapkan oleh rumah sakit. Menurut Depkes RI (2007), pelayanan rekam medis merupakan bagian dari program pengendalian mutu rumah sakit, untuk itu harus ada prosedur baku untuk menilai kualitas pelayanan dan menanggulangi masalah yang timbul.

Menurut Peraturan Menteri Kesehatan RI No. 269/ Menkes/Per/III/2008 tentang Rekam Medis Pasal 1. Rekam medis adalah berkas yang berisikan catatan dan dokumen tentang identitas pasien, pemeriksaan, pengobatan, tindakan dan pelayanan lain yang telah diberikan kepada pasien. Setiap rumah sakit harus membuat rekam medis baik itu rekam medis rawat jalan maupun rekam medis rawat inap. Rekam medis juga berguna sebagai bukti tertulis atas tindakan pelayanan terhadap seorang pasien, juga mampu melindungi kepentingan hukum bagi pasien yang bersangkutan, rumah sakit maupun dokter dan tenaga kesehatan lainnya, apabila di kemudian hari terjadi suatu hal yang tidak diinginkan menyangkut rekam medis itu sendiri. Agar rekam medis dapat digunakan dengan baik maka suatu rumah sakit harus melakukan penyelenggaraan rekam medis.
Penyelenggaraan rekam medis di rumah sakit antara lain pendaftaran, penyimpanan dan pengolahan data rekam medis. Pendaftaran pasien di rumah sakit dibagi menjadi beberapa bagian antara lain pendaftaran pasien rawat jalan, pendaftaran pasien rawat inap dan pendaftaran pasien gawat darurat. Sedangkan menurut kedatangan pasien, pendaftaran di rumah sakit terdiri dari pendaftaran pasien lama dan pendaftaran pasien baru (Depkes RI, 2006).

Pasien adalah seseorang yang menerima perawatan medis, seringkali pasien menderita penyakit atau cedera dan memerlukan bantuan dokter untuk memulihkannya (Imbalo, 2006). Pembayaran pasien di rumah sakit terdiri dari pasien dengan jaminan dan pasien umum atau dengan pembayaran langsung. Pasien umum atau pasien dengan pembayaran langsung adalah pasien tanpa jaminan atau pasien jaminan yang mempunyai tagihan di luar jaminan (Muninjaya, 2013). Setiap pasien yang berobat ke rumah sakit akan mendapatkan dokumen rekam medis yang akan selalu digunakan apabila pasien kembali berkunjung ke rumah sakit yang sama.

Standar Pelayanan Minimal (SPM) adalah ketentuan tentang jenis dan mutu pelayanan dasar yang merupakan urusan wajib daerah yang berhak diperoleh setiap warga secara minimal. Juga merupakan spesifikasi teknis tentang tolak ukur pelayanan yang minimum yang diberikan oleh Badan Layanan Umum kepada masyarakat. Berdasarkan Keputusan Menteri Kesehatan RI No. 129/Menkes/ SK/II/2008 tentang Standar Pelayanan Minimal Rumah Sakit, Standar Pelayanan Minimal (SPM) untuk rekam medis terdiri dari (a) kelengkapan pengisian rekam medis 24 jam setelah selesai pelayanan, (b) kelengkapan informed concent setelah mendapatkan informasi yang jelas, (c) waktu penyediaan dokumen rekam medis pelayanan rawat jalan dan (d) waktu penyediaan dokumen rekam medis pelayanan rawat inap. Dalam penelitian ini, peneliti tertarik melakukan penelitian untuk waktu penyediaan dokumen rekam medis pelayanan rawat jalan berdasarkan standar pelayanan minimal, karena melihat dari kunjungan pasien lama pelayanan rawat jalan yang angkanya lebih tinggi dari pada kunjungan pasien baru di tahun 2014, kurangnya sumber daya manusia dalam penyediaan dokumen rekam medis pasien pelayanan rawat jalan, dan banyaknya dokumen rekam medis pasien yang masih aktif tercecer di lantai karena kurangnya rak penyimpanan sehingga pencarian dokumen rekam medis membutuhkan waktu yang lama. Berdasarkan 
hasil penelitian Indra Sudrajat (2014) di Rumah Sakit Umum Daerah Ciamis ditemukan bahwa kecepatan penyediaan dokumen rekam medis pasien lama di pelayanan rawat jalan dengan jumlah penyediaan dokumen yang cepat sebanyak 35 dokumen (39,77\%) dan penyediaan dokumen rekam medis yang lambat sebanyak 53 dokumen (60,23\%) dari jumlah sampel 88 , dan diketahui rata-rata penyediaan dokumen rekam medis sekitar 20 menit. Maka diketahui bahwa keterlambatan dalam penyediaan dokumen rekam medis pasien lama pelayanan rawat jalan masih menjadi suatu permasalahan yang sering terjadi di suatu rumah sakit.

Rumah Sakit Umum Daerah dr. Soekardjo Kota Tasikmalaya adalah rumah sakit tipe B yang menerima pelayanan rawat jalan, rawat inap dan gawat darurat, pelayanan rawat jalan dilaksanakan pada hari Senin sampai dengan Sabtu dengan rata-rata kunjungan pasien pelayanan rawat jalan perhari sebanyak 355 pasien dan rata-rata kunjungan pasien lama pelayanan rawat jalan sekitar 226 pasien. Berdasarkan studi pendahuluan pada tanggal 20 Januari 2015 di RSUD dr. Soekardjo Kota Tasikmalaya dengan melakukan wawancara kepada petugas rekam medis di bagian filing tentang penyediaan berkas rekam medis pasien rawat jalan, diperoleh informasi bahwa pada pelaksanaan penyediaan dokumen rekam medis pasien rawat lama pelayanan rawat jalan hingga dokumen rekam medis ditemukan masih kurang maksimal, yaitu pada proses penyediaan dokumen rekam medis masih mengalami keterlambatan. Semakin lama penyediaan berkas rekam medis, maka akan menyebabkan terjadinya penumpukan pasien yang menunggu untuk pengambilan dokumen rekam medisnya. Sementara itu RSUD dr. Soekardjo menetapkan Standar Pelayanan Minimal (SPM) d"10 menit dalam penyediaan dokumen rekam medis sampai dokumen rekam medis ditemukan oleh petugas dengan mengacu pada Keputusan Menteri Kesehatan RI No. 129/Menkes/SK/II/2008 tentang Standar Pelayanan Minimal Rumah Sakit. Kemudian peneliti juga melakukan observasi terhadap waktu penyediaan dokumen rekam medis pasien lama pelayanan rawat jalan sebanyak 20 sampel dokumen rekam medis dan diperoleh rata-rata waktu yang dibutuhkan yaitu 13,3 menit. Waktu tersebut menunjukkan belum sesuai dengan standar pelayanan minimal yang telah ditetapkan. Oleh karena itu peneliti mengambil judul penelitian "tinjauan penyediaan dokumen rekam medis pasien lama pelayanan rawat jalan di RSUD dr. Soekardjo Kota Tasikmalaya".

\section{METODE}

Metode yang digunakan dalam penelitian ini merupakan penelitian deskriptif. Teknik pengambilan sampel menggunakan accidental sampling dari populasi yaitu 6809 dokumen rekam medis pasien lama rawat jalan (rata-rata perbulan tahun 2014). Instrumen yang digunakan dalam penelitian ini adalah lembar observasi, stopwatch, pedomana wawancara. Analisis data menggunakan analisis univariat yaitu mendeskripsikan variabel penyediaan dokumen rekam medis pasien lama pelayanan rawat jalan di RSUD dr. Soekardjo dengan analisis deskriptif data numerik dengan menggunakan SPSS dan menggunakan rumus distribusi frekuensi.

\section{HASIL}

\section{Gambaran Waktu Penyediaan Dokumen Rekam Medis Pasien Lama}

Berdasarkan hasil pengumpulan data tentang kecepatan pelayanan penyediaan dokumen rekam medis pasien lama di pelayanan rawat jalan Rumah Sakit Umum Daerah dr. Soekardjo Kota Tasikmalaya diperoleh data sebagai berikut:

Tabel 1 Distribusi Frekuensi Waktu Pelayanan Penyediaan Dokumen Rekam Medis Pasien Lama

\begin{tabular}{clcc}
\hline No. & Kategori waktu & Frekuensi & Prosentase \\
\hline 1. & Cepat & 36 & $36,36 \%$ \\
2. & Lambat & 63 & $63,64 \%$ \\
\hline & Total & 99 & $\mathbf{1 0 0 \%}$ \\
\hline
\end{tabular}

Berdasarkan tabel 1 dapat diketahui bahwa sebanyak 63 dokumen (63,64\%) penyediaan dokumen Rekam Medis Pasien Lama terlambat.

Berdasarkan hasil analisis deskriptif data numerik dengan menggunakan SPSS dapat diketahui bahwa rata-rata waktu yang didapatkan dalam kecepatan penyediaan dokumen rekam medis pasien lama di pelayanan rawat jalan adalah 12 menit 36 detik, dengan standar deviasi 3,13, untuk waktu tercepat adalah 7,20 menit dan waktu terlambat adalah 16,54 menit.

\section{Gambaran Alur Penyediaan Dokumen Rekam Medis Pasien Lama}

Berdasarkan hasil pengumpulan data tentang alur penyediaan dokumen rekam medis pasien lama di pelayanan rawat jalan diperoleh data sebagai berikut: 
Tabel 2 Hasil Oberservasi Alur Penyediaan Dokumen Rekam Medis Pasien Lama di Pelayanan Rawat Jalan

\begin{tabular}{|c|c|c|c|c|c|}
\hline \multirow{2}{*}{ No. } & \multirow{2}{*}{ Tahapan Alur } & \multicolumn{2}{|c|}{ Keterangan } & \multicolumn{2}{|c|}{ Prosentase (\%) } \\
\hline & & Ya & Tidak & Ya & Tidak \\
\hline 1. & Pasien Mendaftar & 99 & 0 & $100 \%$ & $0 \%$ \\
\hline 2. & Pasien mengambil no antrian & 99 & 0 & $100 \%$ & $0 \%$ \\
\hline 3. & Petugas TPP mewawancarai pasien & 99 & 0 & $100 \%$ & $0 \%$ \\
\hline 4. & Petugas melihat no rekam medis pada KIB pasien & 79 & 20 & $79,80 \%$ & $20,20 \%$ \\
\hline 5. & Petugas melakukan entry data pasien & 99 & 0 & $100 \%$ & $0 \%$ \\
\hline 6. & Petugas mencetak print out & 99 & 0 & $100 \%$ & $0 \%$ \\
\hline 7. & Petugas mencari dokumen rekam medis & 99 & 0 & $100 \%$ & $0 \%$ \\
\hline 8. & Karcis pendaftaran dimasukkan ke dalam outguide & 0 & 99 & $0 \%$ & $100 \%$ \\
\hline 9. & Petugas mengeluarkan dokumen rekam medis dari rak filing & 99 & 0 & $100 \%$ & $0 \%$ \\
\hline 10. & $\begin{array}{l}\text { Petugas mencocokan dokumen rekam medis dengan no rekam medis } \\
\text { pasien yang dimaksud }\end{array}$ & 99 & 0 & $100 \%$ & $0 \%$ \\
\hline 11. & $\begin{array}{l}\text { Petugas mengantarkan dokumen rekam medis ke poliklinik yang } \\
\text { dituju }\end{array}$ & 0 & 99 & $0 \%$ & $100 \%$ \\
\hline 12. & $\begin{array}{l}\text { Dokumen rekam medis kembali dengan menggunakan buku } \\
\text { ekspedisi }\end{array}$ & 99 & 0 & $100 \%$ & $0 \%$ \\
\hline
\end{tabular}

Berdasarkan tabel 2 dapat diketahui bahwa tahapan alur pasien mendaftar, pasien mengambil no antrian, petugas Tempat Pendaftaran Pasien mewawancarai pasien, petugas melakukan entry data pasien, petugas mencetak print out, petugas mencari dokumen rekam medis, petugas mengeluarkan dokumen rekam medis dari rak filing, petugas mencocokkan dokumen rekam medis dengan no rekam medis pasien yang dimaksud, dokumen rekam medis kembali dengan menggunakan buku ekspedisi dilakukan pada semua sampel dokumen rekam medis pasien lama di pelayanan rawat jalan sebanyak 99 dengan prosentase $100 \%$, untuk tahapan alur petugas melihat no rekam medis pada KIB pasien dilakukan sebanyak $79(79,80 \%)$ dan tidak dilakukan sebanyak $20(20,20 \%)$, untuk tahapan alur karcis pendaftaran dimasukkan ke dalam outguide dan petugas mengantarkan dokumen rekam medis ke poliklinik yang dituju tidak dilakukan pada semua sampel dokumen rekam medis pasien lama di pelayanan rawat jalan sebanyak 99 dengan prosentase $100 \%$.

Tabel 3 Distribusi Frekuensi Alur Penyediaan Dokumen Rekam Medis Pasien Lama di Pelayanan Rawat Jalan Rumah Sakit Umum Daerah dr. Soekardjo Kota Tasikmalaya Tahun 2015

\begin{tabular}{clll}
\hline No. & Kategori alur & Frekuensi & Prosentase \\
\hline 1. & Sesuai & 0 & $0 \%$ \\
2. & Tidak Sesuai & 99 & $100 \%$ \\
\hline & Total & $\mathbf{9 9}$ & $\mathbf{1 0 0 \%}$ \\
\hline
\end{tabular}

Tabel 3 di atas menunjukkan bahwa alur penyediaan dokumen rekam medis pasien lama di pelayanan rawat jalan dari 99 dokumen rekam medis adalah tidak sesuai dengan prosentase ketidaksesuaiannya yaitu $100 \%$.

\section{PEMBAHASAN}

\section{Gambaran Waktu Penyediaan Dokumen Rekam Medis Pasien Lama}

Berdasarkan hasil wawancara terhadap 3 orang petugas di bagian filing, TPPRJ dan kepala rekam medis diketahui faktor yang menyebabkan keterlambatan dalam penyediaan dokumen rekam medis diantaranya adalah jumlah kunjungan pasien lama yang lebih tinggi dari pada jumlah kunjungan pasien baru, dan jumlah petugas pemberi pelayanan yang terbatas atau masih kurang. Penyebab lain waktu penyediaan dokumen rekam medis menjadi lambat karena fasilitas rak penyimpanan yang kurang dan masih belum cukup untuk menampung dokumen rekam medis sehingga dokumen rekam medis yang masih aktif harus tercecer di bawah lantai, dan menyebabkan sistem penjajaran masih ada yang tidak beraturan sehingga menyulitkan petugas untuk menemukan dokumen rekam medis yang sesuai dengan nomor rekam medisnya, juga karena tidak digunakannya outguide/petunjuk keluar dalam pelaksanaannya sehingga jika ada dokumen rekam medis yang masih di poliklinik petugas tidak akan mengetahuinya. 
Menurut Depkes RI (2007) disebutkan bahwa penyediaan dokumen rekam medis itu adalah mulai dari saat pasien mendaftar sampai dokumen rekam medis disediakan atau ditemukan oleh petugas dengan standar pelayanan minimalnya adalah d"10 menit. Melihat perbandingan standar pelayanan minimal yang ditetapkan oleh rumah sakit dengan kenyataan yang ada maka Rumah Sakit Umum Daerah dr. Soekardjo Kota Tasikmalaya termasuk dalam kategori lambat sebesar 63,64\% dokumen disediakan dalam waktu lebih dari 10 menit.

Dokumen rekam medis yang terlambat sebagian besar ditemukan pada awal pekan (Senin, Selasa, Rabu) sekitar pukul 08.00-10.00 WIB. Hal ini terjadi karena jumlah kunjungan pasien rawat jalan pada hari tersebut meningkat dan lebih banyak dari hari lainnya, sedangkan jumlah petugas penyedia dokumen rekam medis sedikit dan tidak sebanding dengan jumlah kunjungan pasien, maka menyebabkan penyediaan dokumen rekam medis pasien lama pelayanan rawat jalan menjadi terlambat. Adapun dokumen rekam medis yang masuk ke dalam kategori cepat (d"10 menit) biasanya terjadi pada akhir pekan (Kamis, Jumat, Sabtu) sekitar pukul 09.00-11.00 WIB terdapat sebanyak 36 dokumen rekam medis atau sekitar 36,36\% dimana pada hari tersebut jumlah kunjungan pasien rawat jalan lebih sedikit dibandingkan dengan awal pekan, hal ini menyebabkan waktu penyediaan dokumen rekam medis bisa lebih cepat.

\section{Gambaran Alur Penyediaan Dokumen Rekam Medis Pasien Lama}

Berdasarkan hasil wawancara dari 3 orang petugas rekam medis di bagian filing, TPPRJ dan kepala rekam medis menyebutkan bahwa alasan tidak digunakannya petunjuk keluar/outguide karena kondisi rak penyimpanan yang tidak memadai dan kondisi ruangan tempat penyimpanan yang sempit sehingga tidak memungkinkan untuk adanya penambahan rak penyimpanan. Dokumen rekam medis tidak didistribusikan ke poliklinik oleh petugas juga karena jumlah petugas rekam medis yang masih sedikit sedangkan jumlah kunjungan pasien rawat jalan yang banyak atau meningkat.

Tahapan alur penyediaan dokumen rekam medis yang tidak selalu dilakukan, seperti petugas melihat nomor rekam medis pada KIB pasien, hal ini terjadi karena tidak semua pasien lama membawa KIB, ada beberapa pasien yang mengaku bahwa KIBnya tertinggal di rumah ataupun hilang dengan demikian petugas pendaftaran akan mencari data pasien tersebut berdasarkan nama dan alamat yang sesuai, setelah data ditemukan maka nomor rekam medis pasien kembali dicetak.

Selain itu, ditemukan juga tahapan alur penyediaan dokumen rekam medis yang tidak dilakukan sama sekali, yaitu karcis pendaftaran dimasukan ke dalam outguide dan petugas mengantarkan atau mendistribusikan dokumen rekam medis ke poliklinik yang dituju.

Petunjuk keluar adalah suatu alat yang penting untuk mengawasi penggunaan rekam medis. Dalam penggunaannya "Petunjuk Keluar" ini diletakkan sebagai pengganti pada tempat berkas rekam medis yang diambil (dikeluarkan) dari rak penyimpanan. Kartu pinjam/ petunjuk keluar tetap berada di rak file tersebut sampai berkas rekam medis yang diambil (dipinjam) kembali ke tempat semula (Depkes RI, 2006).

Berdasarkan hasil observasi di ruang filing rawat jalan Rumah Sakit Umum Daerah dr. Soekardjo Kota Tasikmalaya tidak menemukan petunjuk keluar/ outguide sebagai mana yang tertera dalam SOP (Standar Operasional Prosedur) peminjaman berkas rekam medis poliklinik rawat jalan dan rawat inap disebutkan setiap peminjaman berkas rekam medis harus melampirkan print out komputer ke dalam petunjuk keluar/outguide.

Petugas mengantarkan/mendistribusikan dokumen rekam medis ke poliklinik yang dituju tidak dilakukan di Rumah Sakit Umum Daerah dr. Soekardjo Kota Tasikmalaya, hal ini tidak sesuai dengan yang tertera pada SOP (Standar Operasional Prosedur) penerimaan pasien lama yang menyebutkan bahwa berkas yang telah ditemukan oleh petugas rekam medis maka langsung diantarkan ke poliklinik yang dituju. Pendistribusian yang dilakukan oleh petugas rekam medis dapat membantu tersedianya dokumen rekam medis secara cepat dibandingkan oleh pasien itu sendiri, karena biasanya ada beberapa pasien yang belum mengetahui letak poliklinik yang akan dituju, berbeda dengan petugas yang biasanya telah hafal lokasi-lokasi atau poliklinik sehingga untuk sampai disana tidak membutuhkan waktu yang lama. Karena semakin cepat dokumen rekam medis sampai ke poliklinik maka akan semakin cepat juga pelayanan medis yang akan diberikan kepada pasien.

Menurut Depkes (2006), pendistribusian dokumen rekam medis ke poliklinik harus dilakukan oleh 
petugas yang memang berwenang untuk membawa dokumen rekam medis pasien. Hal ini untuk meminimalisir terjadinya kebocoran informasi dan keluarnya dokumen rekam medis dari lingkup rumah sakit.

Berdasarkan distribusi frekuensi alur penyediaan dokumen rekam medis pasien lama di pelayanan rawat jalan di Rumah Sakit Umum Daerah dr. Soekardjo Kota Tasikmalaya (Tabel 1.3) diketahui bahwa tidak sesuai karena ada beberapa tahapan alur yang tidak dilakukan seperti penggunaan outguide dan pendistribusian dokumen rekam medis oleh petugas. Karena ketidaksesuaian alur tersebut berdampak pada pelayanan penyediaan dokumen rekam medis yang menjadi terlambat. Karena outguide merupakan salah satu sarana pendukung dalam pelayanan penyediaan dokumen rekam medis.

\section{SIMPULAN}

Berdasarkan penelitian yang dilakukan di Rumah Sakit Umum Daerah dr. Soekardjo Kota Tasikmalaya mengenai pelaksanaan penyediaan dokumen rekam medis pasien lama pelayanan rawat jalan dapat disimpulkan bahwa:

1. Kecepatan penyediaan dokumen rekam medis pasien lama di pelayanan rawat jalan dengan jumlah penyediaan dokumen rekam medis cepat sebanyak 36 dokumen $(36,36 \%)$ dan penyediaan dokumen rekam medis yang lambat sebanyak 63 dokumen $(63,64 \%)$ dari jumlah sampel 99, dan diketahui rata-rata waktu penyediaan dokumen rekam medis sekitar 12,36 menit.

2. Alur penyediaan dokumen rekam medis pasien lama pelayanan rawat jalan tidak sesuai, dimana karcis pendaftaran dimasukkan ke dalam tracer dan petugas mengantarkan dokumen rekam medis ke poliklinik yang dituju tidak dilakukan yaitu sebanyak 99 dokumen (100\%) dari jumlah sampel 99 dokumen rekam medis.

\section{SARAN}

Berdasarkan hasil penelitian maka peneliti memberikan saran bagi Rumah Sakit sebagai berikut :

1. Kualitas pelayanan sebaiknya lebih ditingkatkan khususnya dalam hal kecepatan penyediaan dokumen rekam medis pasien lama di pelayanan rawat jalan agar sesuai dengan SPM (Standar Pelayanan Minimal) yang berlaku, karena dokumen rekam medis merupakan alat bukti pelayanan yang dituntut selalu tersedia saat dibutuhkan oleh pemberi pelayanan kesehatan.

2. Dalam alur penyediaan sebaiknya langkahlangkah pelaksanaan penyediaan dokmen rekam medis pasien lama di pelayanan rawat jalan disesuaikan dengan SOP yang berlaku, dimana penggunaan tracer/petunjuk keluar dan pendistribusian dokumen rekam medis oleh petugas dilakukan untuk meningkatkan kulaitas pelayanan yang cepat dan tepat.

3. Perbaiki sistem penjajaran dokumen rekam medis di pelayanan rawat jalan agar memudahkan petugas dalam melakukan pencarian dan penyediaan dokumen rekam medis.

4. Menyiapkan petugas dalam jumlah lebih banyak pada hari Senin, Selasa dan Rabu karena jumlah kunjungan pada hari-hari tersebut lebih banyak di banding hari-hari lain.

5. Sebaiknya hasil penelitian ini dapat dijadikan bahan pertimbangan bagi pihak rumah sakit dalam proses evaluasi dan pengambilan keputusan.

\section{DAFTAR PUSTAKA}

Azwar, A. 2010. Pengantar Administrasi Kesehatan (Edisi Ketiga). Jakarta: Bina Rupa Aksara.

Budiarto, E. 2002. Biostatistika untuk Kedokteran dan Kesehatan Masyarakat. Jakarta: Buku Kedokteran EGC.

Departemen Kesehatan Republik Indonesia. 2006)\. Pedoman Penyelenggaraan dan Prosedur Rekam Medis Rumah Sakit (Revisi II). Jakarta: Direktorat Jenderal Bina Pelayanan Medik.

2007a. Pedoman Penyelenggaraan Pelayanan Rumah Sakit. Jakarta: Direktorat Jenderal Bina Pelayanan Medik.

2007b. Standar Pelayanan Minimal Rumah Sakit. Jakarta: Direktorat Jenderal Bina Pelayanan Medik.

2009. Sistem Kesehatan Nasional. Jakarta: Direktorat Jenderal Bina Pelayanan Medik.

Hosizah. (2014). Kumpulan Peraturan Perundangan Rekam Medis dan Informasi Kesehatan (MIK). Yogyakarta: aptiRMIK Press.

Imbalo, S. P. 2006. Jaminan Mutu Layanan Kesehatan. Jakarta: EGC. 
Keputusan Menteri Kesehatan No. 129 Tahun 2008 tentang Standar Pelayanan Minimal (SPM) di Rumah Sakit.

Mubarak, W, I dan Chayatin, N. 2009. Ilmu Keperawatan Komunitas Pengantar dan Teori (Buku I). Jakarta: Salemba Medika.

Muninjaya, A. A. Gde. 2013. Manajemen Mutu Pelayanan Kesehatan. Jakarta: EGC.

Notoatmodjo, S. 2010. Metodologi Penelitian Kesehatan. Jakarta: Rineka Cipta.

Peraturan Menteri Kesehatan Republik Indonesia Nomor: 269/MENKES/PER/III/2008 tentang Rekam Medis. 2008. Jakarta: Depkes RI.

Sabarguna, B. 2004. Quality Assurance Pelayanan Rumah Sakit. Jawa Tengah: Konsorsium RS Islam.
Setiawan, A dan Saryono. 2011. Metodologi Penelitian Kebidanan. Yogyakarta: Nuha Medika.

Shofari, B. 2002. Pengelolaan Sistem Rekam Medik 01. Semarang: Perhimpunan Perekam Medik dan Informasi Kesehatan Indonesia.

Siswanto, dkk. 2013. Metodologi Penelitian Kesehatan dan Kedokteran. Yogyakarta: Bursa Ilmu.

Sudrajat, I. 2014. Hubungan Kecepatan Penyediaan Dokumen Rekam Medis Pasien Rawat Jalan Dengan Tingkat Kepuasan Pasien Di Rumah Sakit Umum Daerah Kabupaten Ciamis Tahun 2014. Tasikmalaya: Poltekkes Kemenkes Tasikmalaya: tidak di terbitkan.

Sugiyono. 2012. Statistika Untuk Penelitian. Bandung: CV Alfabeta. 